\title{
NEW RECORDS OF HELMINTHS OF THE CORNCRAKE, CREX CREX (AVES, RALLIDAE) FROM UKRAINE
}

\author{
Ya. Yu. Syrota ${ }^{1,2,4^{*}}$,E. M. Korol ${ }^{3}$, Yu. I. Kuzmin ${ }^{1}$ \\ ${ }^{1}$ Schmalhausen Institute of Zoology, NAS of Ukraine, \\ vul. B. Khmelnitskogo, 15. Kyiv, 01030 Ukraine. Affiliation ID: 60070111 \\ ${ }^{2}$ Kyiv Zoological Park of National Importance, prosp. Peremohy, 32, Kyiv, 04116 Ukraine \\ ${ }^{3}$ National Museum of Natural History, National Academy of Sciences of Ukraine, \\ B. Khmelnytsky St., 15, Kyiv, 01030 Ukraine \\ ${ }^{4}$ African Amphibian Conservation Research Group, Unit for Environmental Sciences and Management, \\ North-West University, Potchefstroom, South Africa \\ ${ }^{*}$ Corresponding author \\ E-mail: sirota@izan.kiev.ua
}

New Records of Helminths of the Corncrake, Crex crex (Aves, Rallidae) from Ukraine. Syrota, Ya. Yu., Korol, E. M., Kuzmin, Yu. I. - The article presents the records and brief descriptions of the trematodes Brachylaima fuscata (Rudolphi, 1819), Prosthogonimus cuneatus (Rudolphi, 1809), Prosthogonimus ovatus (Rudolphi, 1803), and the nematode Cardiofilaria pavlovskyi Ström, 1937 based on the specimens collected from four corncrakes, Crex crex Linnaeus examined on the territory of Ukraine. In the country, P. cuneatus, P. ovatus, and C. pavlovskyi are reported for the first time in this host-species.

Key words: Brachylaima fuscata, Cardiofilaria pavlovskyi, Prosthogonimus cuneatus, Prosthogonimus ovatus, bird, Ukraine.

\section{Introduction}

The corncrake, Crex crex Linnaeus, 1758 breeds in Europe and central Asia, as far east as western China, and winters in sub-Saharan Africa (BirdLife International, 2016). The bird mainly inhabits terrestrial ecosystems, but some freshwater ecosystems are also suitable for this species. Such a life history strategy makes possible the infection of this species with helminths of both waterfowl and of terrestrial birds. Due to this, the corncrake is quite interesting for the helminthological surveys. However, there are only few publications containing the data about helminths of the corncrake in Europe (Macko, 1971; Okulewicz, 1993; Hanzelova and Rysavy, 1999) and the species composition of its helminths was not comprehensively studied on the territory of Ukraine. In the country, the following helminths were previously reported from the corncrake: trematodes 
Brachylaima fuscata (Rudolphi, 1819), Leucochloridium holostomum (Rudolphi, 1819), Echinostoma revolotum group; cestodes Dilepis undula (Schrank, 1788), Rallitaenia pyriformis (Wedl, 1855), Rallitaenia rallida (Macko, 1966) (Greben and Maleha, 2009; Smogorzhevskaya, 1976).

In this article, we present new records of helminths found in the corncrake on the territory of Ukraine with morphological descriptions of the parasites.Prosthogonimus cuneatus (Rudolphi, 1809), P. ovatus (Rudolphi, 1803), and Cardiofilaria pavlovskyi Ström, 1937 are reported from this host for the first time.

\section{Material and methods}

We investigated helminthological material stored in the collection of the I. I. Schmalhausen Institute of Zoology NAS of Ukraine, Kyiv (IZSHK). Helminths were collected from four specimens of the corncrake in JulySeptember of 1973, 1989, and 1999 from the following localities (coordinates are given approximately): Kyiv

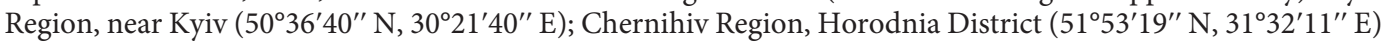
and Nizhyn District $\left(51^{\circ} 00^{\prime} 06^{\prime \prime} \mathrm{N}, 31^{\circ} 54^{\prime} 16^{\prime \prime} \mathrm{E}\right)$. Nematodes were fixed and stored in $4 \%$ formalin solution. For temporary mounts, nematodes were cleared in lactophenol. Trematodes were fixed and stored in $70^{\circ}$ ethanol. For permanent mounts, trematodes were stained in Mayer's haematoxylin. Stained helminths were dehydrated, cleared in clove oil, and mounted in Canadian balsam (Lutz et al., 2017). The specimens were studied under Zeiss Axio Imager M1 light microscope equipped with DIC optics and AmScope T690B microscope. Identification of helminths was based on morphological characters using the keys and the descriptions in Heneberg et al. (2015, 2016), Sonin (1968), and Strom (1937). Measurements in the text are given in micrometres.

\section{Results}

We examined and identified four species of helminths parasitic in the corncrake.

\section{Phylum Platyhelminthes \\ Class Trematoda \\ Family Brachylaimidae}

\section{Brachylaima fuscata (Rudolphi, 1819)}

Six specimens were collected from the intestine of one bird.

Locality: Nizhyn District (Chernihiv Region).

Description (based on 4 mature specimens). Body elongated (fig. 1, A), with maximum width 476-542 anterior to ventral sucker; body length 2,487-2,849. Oral sucker larger than ventral sucker. Oral sucker 241-288×211-282. Ventral sucker 150-182×145-180. Distance from anterior end of body to centre of ventral sucker 890-960. Pharynx well-developed, round, $102-174 \times 123-168$. Gonads in posterior quarter of body. Ovary between testes. Anterior testis 160-272×167-261, posterior testis 164-269×122-245. Ovary 131-162×136171. Vitellarium distributed in two lateral fields, extending from posterior extremity of ventral sucker to level of anterior edge of anterior testis. Eggs oval, numerous, $28-35 \times 16-$ 18 in size.

\section{Family Prosthogonimidae}

\section{Prosthogonimus cuneatus (Rudolphi, 1809)}

Two specimens, one adult and one immature, were collected from the bursa of Fabricius of one bird.

Locality: Horodnia District (Chernihiv Region).

Description of an adult specimen. Body oval (fig. 1, C), 2,072 long, with maximum width 752 atlevel of ovary. Oral sucker subspherical, $191 \times 212$. Ventral sucker $351 \times 360$. Distance from anterior end of body to centre of ventral sucker 930. Pharynx well developed, oval 105×96. Oesophagus short, 120-190 long. Testes elongate-oval. Size of right testis $200 \times 96$, size of left testis $198 \times 90$. Cirrus sac $220 \times 44$. Ovary $220 \times 300$. Ventral sucker slightly overlapping ovary anteriorly. Loops of uteri extending from posterior edge of ventral sucker to posterior end of body. Vitellarium at lateral margins of body. Anterior border of vitellarium at level of posterior edge of ventral sucker, posterior border 

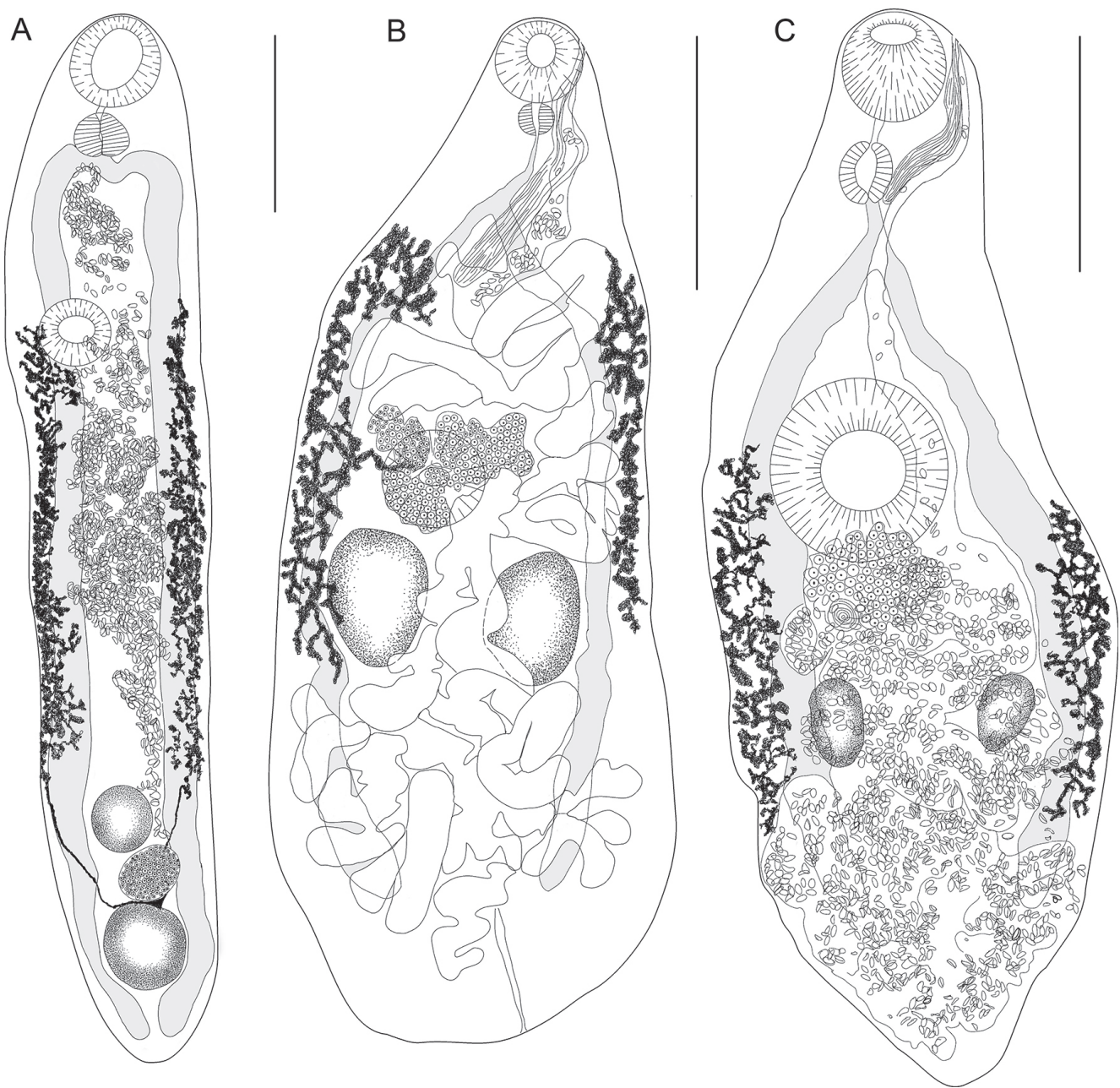

Fig. 1. General view of the trematodes found in the corncrake in Ukraine: Brachylaima fuscata (A), Prosthogonimus ovatus (B), Prosthogonimus cuneatus (C). Scale bars $500 \mu \mathrm{m}$.

of vitellarium posterior to posterior edge of testes. Eggs oval, numerous, $23-25 \times 14-15$ in size.

Description of an immature specimen. Body pear-shaped, 1,425 long, with maximum width 580 at level of testes. Size of oral sucker $168 \times 160$, size of ventral sucker $265 \times 260$. Pharynx $55 \times 35$. Distance from anterior end of body to centre of ventral sucker 660 . Testes round. Right testis $148 \times 150$, left testis $150 \times 153$. Ventral sucker partly covering anterior part of ovary. Ovary $147 \times 178$. Vitellarium undeveloped.

\section{Prosthogonimus ovatus (Rudolphi, 1803)}

One adult specimen was collected from the bursa of Fabricius of one bird.

L o c a lit y: Horodnia District (Chernihiv Region).

Description. Body pear-shaped (fig. 1, B), 1,899 long; its maximum width 735 in posterior quarter. Oral and ventral suckers subspherical. Oral sucker $130 \times 136$. Ventral sucker $250 \times 263$. Distance from anterior end of body to centre of ventral sucker 870 . Pharynx well developed, round, $106 \times 88$. Testes elongate-oval. Right testis $283 \times 220$. Left testis $260 \times 180$. Cirrus-sac $350 \times 80$. Ovary $165 \times 313$. Ventral sucker totally covering ovary. Anterior border of uteri loops distal to intestine bifurcation, posterior border of uteri loops almost at end of body. Anterior edge of vitellarium at level of anterior border of uteri loops. 

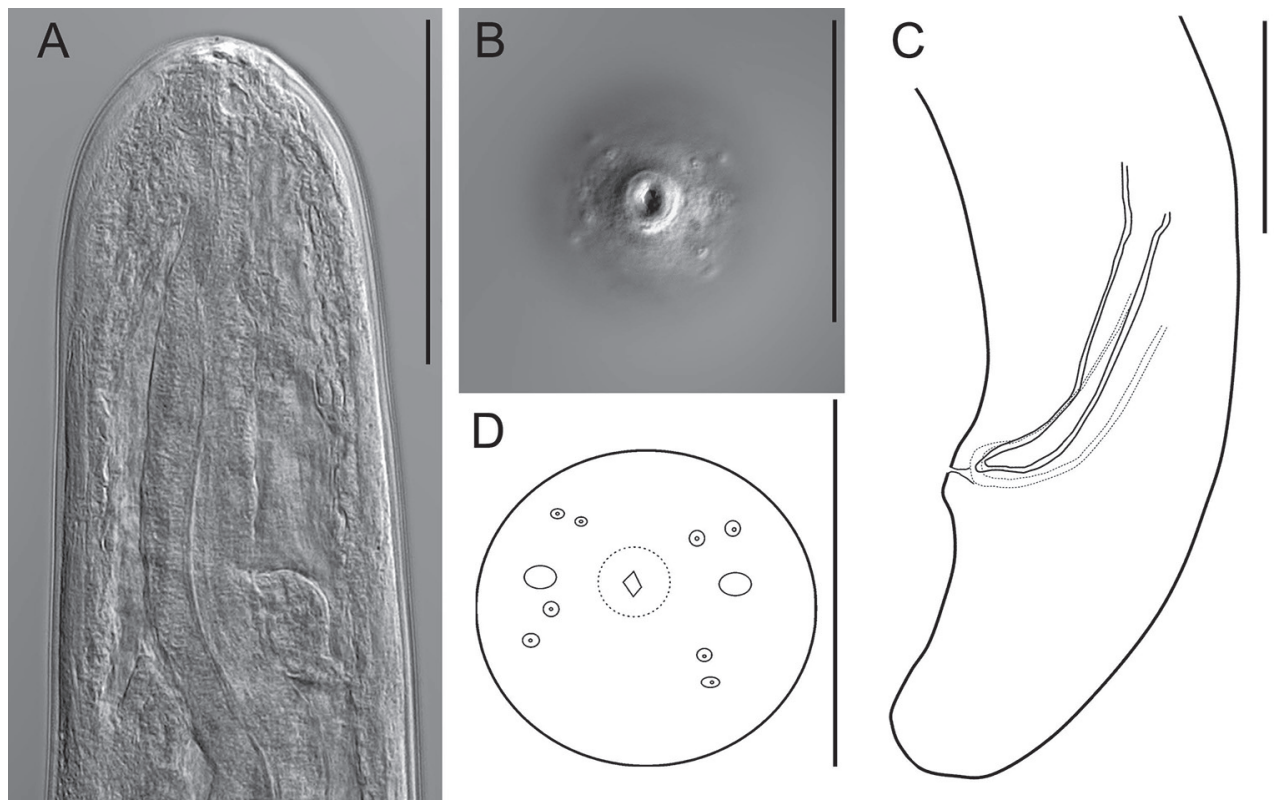

Fig. 2. Cardiofilaria pavlovskyi. A - anterior part of body, lateral view; B - apical view of anterior extremity, optical section at level of cuticular ring; $\mathrm{C}$ - posterior part of body, lateral view; D - position of apical structures (papillae and amphids), en face view. Scale bars $50 \mu \mathrm{m}$.

Branches of vitellarium different in size. One branch extending to middle of testes. Another branch extending to end of testes. Eggs oval, numerous, $25-28 \times 13-14$ in size.

\section{Phylum Nematoda \\ Class Chromadorea \\ Family Onchocercidae}

\section{Cardiofilaria pavlovskyi Ström, 1937}

Two specimens (males) were collected from the air sacs of two birds.

L ocality: Kyiv Region, near Kyiv.

Description of 2 males. Nematodes of small size. Body cylindrical, slightly narrowing to anterior and posterior extremities (fig. 2, A), 6,431-7,485 long. Body width 110-115 at level of posterior edge of oesophagus. Maximum body width 143-165 near middle of body. Cuticle smooth. Mouth small, dorso-ventrally elongated in studied specimens. On anterior extremity, 4 pairs of papillae in two circles and lateral amphids (fig. 2, B, D). Distinct cuticular ring surrounding buccal cavity. Oesophagus divided into muscular and glandular parts, border between parts indistinct. Muscular part of oesophagus 48-51 long, glandular part 355-377 long. Nerve ring in first quarter of glandular part of oesophagus, 127-136 from anterior extremity. Spicules subequal and slightly dissimilar (fig. 2, C). Left spicule 75-81 long, right spicule 60-65 long. Tail short and blunt, 69-76 long.

\section{Discussion}

Our record of $B$. fuscata is the second registration of this species in the corncrake from Ukraine. The first record (Greben and Maleha, 2009) is somewhat insufficiently documented; it was presented just as an item in a species list without any illustrations or description of morphology. In Ukraine, this helminth is also known from Pluvialis apricaria (Linnaeus), Sturnus vulgaris Linnaeus, and Garrulus glandarius Linnaeus (Iskova et al., 1995). The species was found in game fowl, doves, pigeons and passeriform birds, rarely also in birds 
Table 1. Metrical characters of Prosthogonimus cuneatus and P. ovatus

\begin{tabular}{l|c|c|c|c|c|c}
\hline \multirow{2}{*}{ Characters } & \multicolumn{3}{c|}{ Prosthogonimus cuneatus } & \multicolumn{3}{c}{ Prosthogonimus ovatus } \\
\cline { 2 - 7 } & $\begin{array}{c}\text { from } \\
\text { Crex crex, } \\
\text { present } \\
\text { study }\end{array}$ & $\begin{array}{c}\text { from various } \\
\text { hosts, in } \\
\text { Heneberg et } \\
\text { al. (2015) }\end{array}$ & $\begin{array}{c}\text { from Corvus } \\
\text { cornix, in } \\
\text { Sharpilo \& } \\
\text { Iskova (1989) }\end{array}$ & $\begin{array}{c}\text { from Crex } \\
\text { crex, present } \\
\text { study }\end{array}$ & $\begin{array}{c}\text { from } \\
\text { various } \\
\text { hosts, in } \\
\text { Heneberg et } \\
\text { al. (2015) }\end{array}$ & $\begin{array}{c}\text { from Pica } \\
\text { pica, in } \\
\text { Sharpilo } \\
\text { \& Iskova } \\
(1989)\end{array}$ \\
\hline Body length & $\mathrm{n}=1$ & $\mathrm{n}=15$ & $\mathrm{n} / \mathrm{a}$ & $\mathrm{n}=1$ & $\mathrm{n}=30$ & $\mathrm{n} / \mathrm{a}$ \\
Body width & 2,072 & $4,147-5,148$ & $5,840-7,040$ & 1,899 & $3,289-5,634$ & $3,820-5,520$ \\
Oral sucker length & 752 & $1,714-3,661$ & $3,200-3,580$ & 735 & $1,543-2,229$ & $1,820-2,250$ \\
Oral sucker width & 191 & $238-534$ & $520-540$ & 130 & $122-340$ & $190-210$ \\
Ventral sucker length & 212 & $267-598$ & $520-540$ & 136 & $139-340$ & $170-190$ \\
Ventral sucker width & 351 & $493-920$ & $800-880$ & 250 & $319-460$ & $410-440$ \\
Pharynx length & 360 & $522-920$ & $800-880$ & 263 & $348-460$ & $410-440$ \\
Pharynx width & 105 & $128-276$ & $320-330$ & 106 & $99-202$ & $130-150$ \\
Left testis length & 96 & $133-244$ & $300-320$ & 88 & $93-193$ & $130-150$ \\
Left testis width & 198 & $478-810$ & $1,180-1,360$ & 260 & $348-1118$ & $810-900$ \\
Right testis length & 90 & $267-754$ & $1,040-1,120$ & 180 & $174-745$ & $600-640$ \\
Right testis width & 200 & $478-775$ & $1,180-1,360$ & 283 & $290-1088$ & $810-900$ \\
Ovary length & 96 & $232-662$ & $1,040-1,120$ & 220 & $174-745$ & $600-640$ \\
Ovary width & 220 & $319-1311$ & $\mathrm{n} / \mathrm{a}$ & 165 & $368-736$ & $\mathrm{n} / \mathrm{a}$ \\
Egg length & 300 & $248-1118$ & $\mathrm{n} / \mathrm{a}$ & 313 & $184-920$ & $\mathrm{n} / \mathrm{a}$ \\
Egg width & $23-25$ & $26-34$ & $24-28$ & $25-28$ & $29-34$ & $21-24$ \\
\hline
\end{tabular}

of prey and owls in the Nearctic and Western Palaearctic regions (Heneberg et al., 2016; Gibson et al., 2005).

Prosthogonimus cuneatus and P. ovatus are cosmopolitan parasites of young birds of various orders (Sharpilo and Iskova, 1989). These helminths are often found in waterfowl (Heneberg et al., 2015). Prior to our studies, these two species have never been recorded in the corncrake on the territory of Ukraine or elsewhere. The studied specimens differed from those described in the literature in most metrical characters (table 1). We suggest that smaller size of the studied specimens is related to the relatively small size of the host. However, the qualitative characters (position of the ovary relatively to the ventral sucker, position of the vitellarium relatively to the testes and the ventral sucker, position of the uterine

Table 2. Metrical characters of Cardiofilaria pavlovskyi males

\begin{tabular}{l|c|c|c|c}
\hline \multicolumn{1}{c|}{ Characters } & $\begin{array}{c}\text { From Crex } \\
\text { crex, pres- } \\
\text { ent study }\end{array}$ & $\begin{array}{c}\text { From Corvus } \\
\text { brachyrhynchos, in } \\
\text { Bartlett \& Anderson } \\
(1980)\end{array}$ & $\begin{array}{c}\text { From Orioluso- } \\
\text { riolus, in Strom } \\
\text { (1937) } \\
\text { after Sonin, } \\
1968)\end{array}$ & $\begin{array}{c}\text { From Hirundapus } \\
\text { caudacutus, in } \\
\text { Sonin (1963) } \\
\text { (after Sonin, 1968) }\end{array}$ \\
\hline Body length & $\mathrm{n}=2$ & $\mathrm{n}=25$ & $\mathrm{n} / \mathrm{a}$ & $\mathrm{n} / \mathrm{a}$ \\
Body width at mid-body & $6,431-7,485$ & $6,500-8,800$ & 7,500 & 7,800 \\
Muscular oesophagus length & $143-165$ & $105-184$ & 150 & 180 \\
Glandular oesophagus length & $35-51$ & $\mathrm{n} / \mathrm{a}$ & $\mathrm{n} / \mathrm{a}$ & $\mathrm{n} / \mathrm{a}$ \\
Total length of oesophagus & $455-377$ & $\mathrm{n} / \mathrm{a}$ & $\mathrm{n} / \mathrm{a}$ & 500 \\
Nerve ring & $127-136$ & $176-250 *$ & 400 & 150 \\
Right spicule & $60-65$ & $140-194$ & 175 & 60 \\
Left spicule & $75-81$ & $54-76$ & 69 & 70 \\
Tail & $69-76$ & $56-84$ & 80 & 60 \\
\hline
\end{tabular}

* Presumably, incorrect measurements. 
loops relatively to the ventral sucker and branches of the caecum) allowed to identify the studied specimens unambiguously.

Cardiofilaria pavlovskyi was found in Europe, Asia and North America in a fairly wide range of bird-hosts belonging to Passeriformes, Falconiformes, Apodiformes, and Charadriiformes (Sitko and Okulewicz, 2010). On the territory of Ukraine, this species was previously registered in the European honey buzzard, Pernis apivorus (Linnaeus) (Smogorzhevskaya and Sharpilo, 1984). The morphological characters in the studied male specimens appeared to correspond to the characteristics inherent to this species (table 2).

Thus, we report on three helminths which had not previously been recorded in the corncrake in the world and on the territory of Ukraine. We also confirmed the parasitism of B. fuscata in the corncrake in Ukraine.

Microscopic studies were done using the equipment of the Centre of collective use of scientific equipment "Animalia" (Institute of Zoology, NAS of Ukraine).

\section{References}

Bartlett, C. M., Anderson, R. C. 1980. Filarioid nematodes (Filarioidea: Onchocercidae) of Corvus brachyrhynchos brachyrhynchos Brehm in southern Ontario, Canada and a consideration of the epizootiology of avian filariasis. Systematic Parasitology, 2 (1), 77-102.

BirdLife International. 2016. Crex crex. The IUCN Red List of Threatened Species 2016: e.T22692543A86147127. http://dx.doi.org/10.2305/IUCN.UK.2016-3.RLTS.T22692543A86147127.en. Downloaded on 06 July 2018.

Gibson, D. I., Bray, R. A., Harris, E. A. 2005. Host Parasite Database of the Natural History Museum, London. Available from: http://www.nhm.ac.uk/research-curation/scientific-resources/taxonomy-systematics/ host-parasites/database/index.jsp? (July 2018)

Greben, O. B., Maleha, A. M. 2009. Fauna of flatworms in Corncrake (Crex crex L.) from Ukraine. In: XIV conference of Ukrainian scientific society of parasitologists (Uzhgorod, 21-24 September 2009). Kyiv, 29 [In Russian].

Hanzelova, V., Rysavy, B. 1999. Synopsis of cestodes in Slovakia. V. Dilepididae, Dipylidiidae and Paruterinidae. Helminthologia, 36 (2), 111-117.

Heneberg, P., Sitko, J., Bizos, J. 2015. Integrative taxonomy of central European parasitic flatworms of the family Prosthogonimidae Lühe, 1909 (Trematoda: Plagiorchiida). Parasitology International, 64 (5), 264-273.

Heneberg, P., Sitko, J., Bizos, J. 2016. Molecular and comparative morphological analysis of central European parasitic flatworms of the superfamily Brachylaimoidea Allison, 1943 (Trematoda: Plagiorchiida). Parasitology, 143 (4), 455-474.

Iskova, N. I., Sharpilo, V. P., Sharpilo, L. D., Tkach, V. V. 1995. Catalogue of the helminths of Ukrainian vertebrates. Trematodes of terrestrial vertebrates. Kiev, 1-93.

Lutz, H. L., Tkach, V. V., Weckstein, J. D., Webster, M. S. 2017. Methods for Specimen-based Studies of avian Symbionts. In: Michael, S. W., ed. The Extended Specimen: Emerging Frontiers in Collections-based Ornithological Research. CRC Press, Boca Raton, 157-183.

Macko, J. K. 1971. The helminth fauna of Crex crex from East Slovakia. Helminthologia, 10, 297-305.

Okulewicz, A. 1993. Capillariinae (Nematoda) palearktycznych ptaków. Wydawn. Uniwersytetu Wrocławskiego, 1-147 [In Polish].

Sharpilo, V., Iskova, N. 1989. Fauna of Ukraine, Vol. 34, issue 3. Trematodes of the suborder Plagiorchiata. Naukova Dumka, Kiev, 1-277 [In Russian].

Sitko, J., Okulewicz, A. 2010. Checklist of the Nematodes in Birds in the Czech Republic and the Slovak Republic. Comenius Museum, Přerov, 1-100.

Smogorzhevskaya, L. A. 1976. Helminths of aquatic and marsh birds of the fauna of Ukraine. Naukova dumka, Kiev, 1-416 [In Russian].

Smogorzhevskaya, L. A., Sharpilo, V. P. 1984. On study of nematodes birds of prey and owls of Ukraine. Vestnik Zoologii. (2), 81-82 [In Russian].

Sonin, M. D. 1963. Filaria of birds in Far-Eastern USSR. In: Trudy Gel'mintologicheskoi Laboratorii Akademiya Nauk SSSR, 13, 227-249 [In Russian].

Sonin, M. D. 1968. Essentials of nematology. Vol. XXI. Filariata of animals and man and the diseases caused by them. Diplotriaenoidea. Nauka, Moscow, 1-391 [In Russian].

Strom, Z. K. 1937. A new nematode of birds Cardiofilaria pavlovskyi n. gen., n. sp. In: Trudy Sov. Izuch. Proizvod. Sil. Ser. Turkm, 9. 217-221 [In Russian].

Received 1 August 2018

Accepted 25 October 2019 